\title{
ANALISIS KASUS PENURUNAN PONDASI JARINGAN TRANSMISI 150KV KALIMANTAN TIMUR
}

\author{
Ray Prosper Intan ${ }^{1}$ dan Gregorius Sandjaja Sentosa ${ }^{2}$ \\ ${ }^{1}$ Program Studi Sarjana Teknik Sipil, Universitas Tarumanagara, Jl. Letjen S. Parman No.1 Jakarta \\ rayi.ts@stu.untar.ac.id \\ ${ }^{2}$ Program Studi Sarjana Teknik Sipil, Universitas Tarumanagara, Jl. Letjen S. Parman No.1 Jakarta \\ gregorius@ft.untar.ac.id
}

Masuk: 29-06-2020, revisi: 06-07-2020, diterima untuk diterbitkan: 05-08-2020

\begin{abstract}
Electricity is undeniably a primary need for all human beings in the world after water, land, and air. The more developed a country is, the higher the need for electricity will be. To keep up with the demands, power plants which are built, mostly in rural areas. The generated electricity is then delivered to consumers through transmission networks. A transmission network is needed to deliver the electricity from plants to consumers. Electricity generated by the power plants is channeled through electricity transmission, which is connected by using electric towers. The terrain of the construction of the electric transmission tower is very diverse; and the soil types upon which the towers are built greatly affect the stability of the tower's foundation. The tower's foundation should be able to withstand the weight of the transmission networks, so that towers stability should not interfere with electricity distributions process. This study aims to analyze the foundational decline that occurred in the transmission tower in East Kalimantan that was built on peat soil.
\end{abstract}

Keywords:borepile; settlement; electricity tower; foundation; peat soil

\begin{abstract}
ABSTRAK
Listrik tidak dapat dipungkiri sudah menjadi kebutuhan primer bagi seluruh umat manusia di dunia setelah air, tanah, dan udara. Semakin maju sebuah negara maka kebutuhan akan listrik negara tersebut akan semakin tinggi, oleh karena itu negara harus mampu untuk menyediakan kebutuhan listrik itu. Kebutuhan listrik tersebut dapat dipenuhi dengan membangun pembangkit-pembangkit listrik, pada umumnya pembangkit listrik dibangun di daerah pinggiran kota. Ketika pembangkit-pembangkit listrik tersebut yang telah dibangun dan telah menghasilkan listrik maka diperlukan jaringan transmisi listrik untuk menyalurkan listrik yang telah dihasilkan tersebut. Jaringan transmisi listrik tersebut melalui tower-tower listrik. Medan pembangunan tower tower transmisi listrik tersebut sangat beragam, kondisi alam, jenis tanah sangat mempengaruhi dalam pembangunan pondasi tower listrik. Pondasi listrik tersebut harus mampu untuk memikul beban yang akan dibebani pada pondasi dan tidak terjadi kegagalan agar tower transmisi tetap kokoh dan tidak menganggu proses penyaluran transmisi tersebut akibat pondasi yang tidak mampu memikul. Penelitian ini bertujuan untuk menganalisa penurunan yang akan terjadi pada pondasi tower transmisi yang telah dibangun di Kalimantan timur yang mempunyai kondisi tanah gambut dan mengalimi penurunan setelah pondasi selesai dibangun.
\end{abstract}

Kata kunci: tiang bor; penurunan; tower listrik; pondasi; tanah gambut

\section{PENDAHULUAN}

Pemerintah saat ini tengah gencar merealisasikan ketersediaan energi listrik sebesar 35000 megawatt (mw) untuk mendukung pertumbuhan ekonomi di indonesia. Dalam pembangunan itu tentu berbagai masalah dihadapi oleh kontraktor, salah satunya persoalaan geoteknik. Pada geoteknik bisa terjadi berbagai persoalan seperti tanah longsor, tanah lunak, tanah ekspansif dan sebagainya.

Salah satu proyek dari rencana penyediaan sumber daya listrik 35000 Megawatt (MW) menjadi perhatian penulis. Proyek yang menjadi perhatian penulis adalah pembangunan jaringan trasnmisi 150 kiloVolt (kV) di Kalimantan timur, karena terjadi penurunan pondasi sebesar $13 \mathrm{~cm}$ pada salah satu tower jaringan transmisi. Pada studi kasus ini akan menghitung besarnya penurunan dengan pendekatan analitik. Sumber data dari penelitian ini berasal dari suatu institusi yang meminta dirahasiakan identitasnya. 
Tujuan dari penelitian ini untuk mengetahui besar penurunan fondasi yang terjadi pada jaringan transmisi SUTET dengan menggunakan metode analitik yang akan dibandingkan dengan penurunan yan terjadi di lapangan sehingga dapat menentukan apakah penurunan yang terjadi di lapangan masih akan terjadi.

Dasar teori dari penelitian ini adalah jika tanah diberi beban maka tanah akan memadat yang disebabkan keluarnya air pori dari dalam tanah yang kemudian akibat keluarnya air pori tersebut kemudian bisa menyebabkan turunnya pondasi. Besar pemadatan yang terjadi kemudian di cari tahu agar bisa diketahui besar penurunan yang akan terjadi jika telah dibebani.

\section{Elastic settlement}

Elastic settlement adalah penurunan yang terjadi akibat pembebanan yang diberikan biasanya dalam jangka waktu yang pendek. Analisa penurunan elastik pondasi tiang dilakukan dengan metode (Poulos \& Davis, 1980). Perhitungan dilakukan berdasarkan persamaan untuk floating pile dan end bearing pile:

$$
\rho: \frac{\mathrm{P} \cdot \mathrm{I}}{\mathrm{E}_{\mathrm{S}} \cdot \mathrm{d}}
$$

dengan $\rho$ = penurunan kepala tiang $(\mathrm{m}), \mathrm{P}=$ beban aksial yang bekerja $(\mathrm{kN}), \mathrm{I}=\mathrm{I}_{\mathrm{o}} \cdot \mathrm{R}_{\mathrm{k}} \cdot \mathrm{R}_{\mathrm{h}} \cdot \mathrm{R}_{\mathrm{v}}$ untuk floating pile, $\mathrm{I}=$ $\mathrm{I}_{\mathrm{o}} \cdot \mathrm{R}_{\mathrm{k}} \cdot \mathrm{R}_{\mathrm{b}} \cdot \mathrm{R}_{\mathrm{v}}$ untuk end bearing pile, $\mathrm{I}_{\mathrm{o}}=$ faktor pengaruh penurunan tiang untuk $\mathrm{v}_{\mathrm{s}} 0.5, \mathrm{R}_{\mathrm{k}}=$ faktor koreksi untuk kompresibilitas tiang, $\mathrm{R}_{\mathrm{h}}=$ faktor koreksi untuk kedalaman lapisan tanah hingga tanah keras, $\mathrm{R}_{\mathrm{v}}=$ faktor koreksi untuk poisson's ratio tanah, $\mathrm{R}_{\mathrm{b}}=$ faktor Koreksi Stiffness Bearing Stratum

\section{Consolidation settlement}

Consolidation settlement adalah penurunan yang terjadi secara perlahan karena adanya perubahan volume tanah selama periode keluarnya air dari pori-pori tanah, penurunan terjadi akibat pemampatan tanah yang disebabkan oleh penyesuaian butir-butir tanah. Kemudian besarnya nilai konsolidasi dapat ditentukan dengan (Terzaghi \& Peck, 1967):

$$
\mathrm{Sc}=\frac{\mathrm{Cc} \cdot \mathrm{H}}{1+\mathrm{eo}} \log \frac{\sigma o+\Delta \mathrm{o}}{\sigma 0}
$$

dengan $\mathrm{H}=$ tebal lapisan tanah, $\mathrm{eo}=$ void ratio, $\mathrm{Cc}=$ compression index, $\sigma \mathrm{o}=$ tegangan efektif tanah sebelum pembebanan, $\Delta \mathrm{o}=$ besar nilai tambahan tegangan

\section{METODE PENELITIAN}

\section{Metode pengumpulan data}

Metode yang digunakan dalam pengumpulan data adalah dari hasil sondir yang kemudian akan dikorelasikan agar memperoleh parameter tanah yang kira-kira sesuai serta dari as build drawing yang diperoleh dari kontraktor yang akan digunakan untuk mengetahui besaran beban yang akan diterima.

\section{Metode analisis perhitungan penurunan fondasi}

Metode analisis yang akan digunakan untuk menganalisis data menggunakan rumus penurunan elastis untuk mengetahui besaran penurunan elastis dan rumus penurunan konsolidasi untuk mengetahui besar penurunan konsolidasi. Kemudian total penurunan dijumlahkan dari penurunan elastis dan penurunan konsolidasi. Sebelum dilakukan analisis data perlu adanya studi literature dengan mencari dasar-dasar teori dan sumber data untuk mendapatkan rumus-rumus.

\section{HASIL DAN PEMBAHASAN}

\section{Kesimpulan elastic \& consolidation settlement}

Berdasarkan hasil data tes sondir yang telah diperoleh, data tersebut digunakan untuk menghitung total besar penurunan yang terjadi. Besar penuruna dibagi atas 2 jenis penurunan yaitu penurunan elastic dan konsolidasi. Kurangnya data yang diperoleh maka beberapa parameter diasumsikan setelah dilakukan studi literatur. 


$$
\begin{aligned}
\mathrm{Eb} & =20487 \mathrm{MPa} \\
\mathrm{Es} \quad & =5 \times \mathrm{qc} \\
& =5 \times 47.18 \mathrm{~kg} / \mathrm{cm}^{2} \\
& =235,9 \mathrm{~kg} / \mathrm{cm}^{2} \\
& =23,1338 \mathrm{MPa} \\
& =23133,8 \mathrm{kN} / \mathrm{m}^{2}
\end{aligned}
$$

$$
\text { Vs }=0,35
$$$$
\mathrm{P} \quad=\frac{958.1}{4}
$$$$
=239,525 \mathrm{kN}
$$

$\mathrm{R}_{\mathrm{A}}=1$

$\mathrm{K}=\frac{E_{B} \cdot R_{A}}{E_{S}}$

$$
\begin{aligned}
& =\frac{20487 \times 1}{23.1338} \\
& =885,5873
\end{aligned}
$$

$\mathrm{I}_{\mathrm{o}} \quad=0,065$

$\mathrm{R}_{\mathrm{k}} \quad=1,45$

$\mathrm{R}_{\mathrm{b}} \quad=0,7$

$\mathrm{R}_{\mathrm{v}} \quad=0,95$

I $\quad=0,065 \times 1,45 \times 0,7 \times 0,95$

$=0,06267$

$\rho=\frac{239.525 \times 0.06267}{23133.8 \times 0.6}$

$=0,001081 \mathrm{~m}$

$=0,1081 \mathrm{~cm}$ 
Sehingga untuk tip tower 3 penurunan elastis yang terjadi setelah dilakukan perhitungan dengan menggunakan formula Poulos \& Davis (1980) adalah 0,1641 cm.

Pada tip tower 3 bidang fiktif fondasi diasumsikan sebagai tiang tunggal dan dibagi menjadi 5 lapisan dengan membentuk sudut perbadingan dalam membuat bidang fiktif yang digunakan perbadingan yaitu 1:4 sehingga hasil analisis didapatkan :

-Lapisan 1 (2,5-5 m)

$$
\begin{array}{ll}
\text { Nilai qc rata-rata } & =2,565 \mathrm{~kg} / \mathrm{cm}^{2} \\
& =2,5154 \mathrm{Bar} \\
\text { Nilai Cc } & =0,2 \text { (asumsi) } \\
\text { Nilai eo } & =0,8 \text { (asumsi) } \\
\text { Tebal Lapisan (h) } & =2,5 \mathrm{~m} \\
\text { Nilai } \gamma \text { saturated } & =16,5 \\
\text { Nilai } \sigma_{0} & =(\gamma \text { saturated }-1) \times h \\
& =(16,5-10) \times 2,5 \\
& =16,25 \mathrm{kN} / \mathrm{m}^{2} \\
\text { Besar beban P } & =(\text { volume tiang bor } \times \text { berat jenis beton }) \\
& =\left(\left(\left(0,2827 \mathrm{~m}^{2} \times 2,5 \mathrm{~m}\right) \times 24 \mathrm{kN} / \mathrm{m}^{3}\right) \times 4\right) \\
\text { Diameter bidang fiktif } & =178,4509 \mathrm{kN} \\
& =185 \\
& =, 85 \mathrm{~m} \\
\text { Luas (A) } & =\frac{1}{4} \times \pi \times \mathrm{r}^{2} \\
& =\frac{1}{4} \times \pi \times 1,85^{2} \\
& =2,688 \mathrm{~m}^{2} \\
\text { Consolidation } & =\frac{P}{A} \\
& =\frac{178.4509 \mathrm{kN}}{2.688 \mathrm{~m}^{2}} \\
& =66,38736 \mathrm{kN} / \mathrm{m}^{2} \\
& =\frac{C c . H}{1+e o} \log \frac{\sigma o+\Delta o}{\sigma 0} \\
& =\frac{0.2 \times 2.5}{1+0.8} \log \frac{16.25+66.3876}{16.25} \\
& =0,1962 \mathrm{~m} \\
& =19,62 \mathrm{~cm} \\
\text { Nilai } \Delta \sigma &
\end{array}
$$

-Lapisan 2 (5-10 m)

$$
\begin{array}{ll}
\text { Nilai qc rata-rata } & =2,955 \mathrm{~kg} / \mathrm{cm}^{2} \\
& =2,937 \mathrm{Bar} \\
\text { Nilai Cc } & =0,2(\text { asumsi) }
\end{array}
$$




$$
\begin{aligned}
& \text { Nilai eo } \quad=0,8 \text { (asumsi) } \\
& \text { Tebal Lapisan }(\mathrm{h}) \quad=5 \mathrm{~m} \\
& \text { Nilai } \gamma s \text { aturated } \quad=16.5 \\
& \text { Nilai } \sigma_{0} \quad=(\text { rsaturated }-1) \times h \\
& =(16.5-10) \times 5 \\
& =32,5 \mathrm{kN} / \mathrm{m}^{2} \\
& \text { Besar beban } \mathrm{P} \quad \text { = (volume tiang bor } \times \text { berat jenis beton }) \\
& =\left(\left(\left(0,2827 \mathrm{~m}^{2} \times 5 \mathrm{~m}\right) \times 24 \mathrm{kN} / \mathrm{m}^{3}\right) \times 4\right) \\
& =246,3093 \mathrm{kN} \\
& \text { Diameter bidang fiktif } \quad=435 \mathrm{~cm} \\
& =4,35 \mathrm{~m} \\
& \text { Luas (A) } \\
& =\frac{1}{4} \times \pi \times r^{2} \\
& =\frac{1}{4} \times \pi \times 4.35^{2} \\
& =14,8617 \mathrm{~m}^{2} \\
& \text { Nilai } \Delta \sigma \quad=\frac{P}{A} \\
& =\frac{246.3093 \mathrm{kN}}{14.8617 \mathrm{~m}^{2}} \\
& =16,5734 \mathrm{kN} / \mathrm{m}^{2} \\
& =\frac{C c \cdot H}{1+e o} \log \frac{\sigma o+\Delta o}{\sigma 0} \\
& =\frac{0.2 \times 5}{1+0.8} \log \frac{32.5+16.5734}{32.5} \\
& =0,09942 \mathrm{~m} \\
& =9,942 \mathrm{~cm}
\end{aligned}
$$

-Lapisan 3 (10-15 m)

$$
\begin{array}{ll}
\text { Nilai qc rata-rata } & =4.2034 \mathrm{~kg} / \mathrm{cm}^{2} \\
& =4,1221 \mathrm{Bar} \\
\text { Nilai Cc } & =0,2(\text { asumsi }) \\
\text { Nilai eo } & =0,8 \text { (asumsi }) \\
\text { Tebal Lapisan }(\mathrm{h}) & =5 \mathrm{~m} \\
\text { Nilai } \gamma s \text { aturated } & =16,5 \\
\text { Nilai } \sigma_{0} & =(\gamma \text { saturated }-1) \times h \\
& =(16.5-10) \times 5 \\
& =32,5 \mathrm{kN} / \mathrm{m}^{2} \\
\text { Besar beban P } & =(\text { volume tiang bor } \times \text { berat jenis beton }) \\
& =\left(\left(\left(0,2827 \mathrm{~m}^{2} \times 5 \mathrm{~m}\right) \times 24 \mathrm{kN} / \mathrm{m}^{3}\right) \times 4\right) \\
& =382.0261 \mathrm{kN} \\
\text { Diameter bidang fiktif } & =685 \mathrm{~cm} \\
& =6,85 \mathrm{~m}
\end{array}
$$


Luas (A)

Nilai $\Delta \sigma$

Consolidation

Nilai qc rata-rata

Nilai Cc

Nilai eo

Tebal Lapisan (h)

Nilai $\gamma s$ aturated

Nilai $\sigma_{0}$

Besar beban $\mathrm{P}$

Nilai $\Delta \sigma$

Consolidation

$$
\begin{aligned}
& =\frac{1}{4} \times \pi \times \mathrm{r}^{2} \\
& =\frac{1}{4} \times \pi \times 6,85^{2} \\
& =36,8528 \mathrm{~m}^{2}
\end{aligned}
$$$$
=\frac{P}{A}
$$$$
=\frac{382.0261 \mathrm{kN}}{36.8528 \mathrm{~m}^{2}}
$$$$
=10,3626 \mathrm{kN} / \mathrm{m}^{2}
$$$$
=\frac{C c \cdot H}{1+e o} \log \frac{\sigma o+\Delta o}{\sigma 0}
$$$$
=\frac{0.2 \times 5}{1+0.8} \log \frac{32.5+10.3626}{32.5}
$$$$
=0,06679 \mathrm{~m}
$$$$
=6,679 \mathrm{~cm}
$$

-Lapisan 4 (15-19 m)

$$
\begin{aligned}
& =4.9638 \mathrm{~kg} / \mathrm{cm}^{2} \\
& =4.8678 \text { Bar } \\
& =0,7 \text { (asumsi) } \\
& =0,8 \text { (asumsi) } \\
& =4 \mathrm{~m} \\
& =16,5 \\
& =(\gamma \text { saturated }-1) \times h \\
& =(16.5-10) \times 4 \\
& =26 \mathrm{kN} / \mathrm{m}^{2}
\end{aligned}
$$

$=($ volume tiang bor $\times$ berat jenis beton $)$

$=\left(\left(\left(0.2827 \mathrm{~m}^{2} \times 4 \mathrm{~m}\right) \times 24 \mathrm{kN} / \mathrm{m}^{3}\right) \times 4\right)$

$=517,7429 \mathrm{kN}$

Diameter bidang fiktif $\quad=885 \mathrm{~cm}$

$$
=8,85 \mathrm{~m}
$$$$
=\frac{1}{4} \times \pi \times \mathrm{r}^{2}
$$$$
=\frac{1}{4} \times \pi \times 8.85^{2}
$$$$
=61,5143 \mathrm{~m}^{2}
$$

$$
=\frac{P}{A}
$$

$$
\begin{aligned}
& =\frac{517.7429 \mathrm{kN}}{61.5143 \mathrm{~m}^{2}} \\
& =8,4162 \mathrm{kN} / \mathrm{m}^{2}
\end{aligned}
$$

$=\frac{C c \cdot H}{1+e o} \log \frac{\sigma o+\Delta o}{\sigma 0}$

$=\frac{0.2 \times 4}{1+0.8} \log \frac{26+8.4162}{26}$

$=0,05413 \mathrm{~m}$ 


$$
=5,413 \mathrm{~cm}
$$

Sc

$$
\begin{aligned}
& =\text { Lapisan 1+ Lapisan 2+ Lapisan } 3+\text { Lapisan } 4 \\
& =0,1962+0,09942+0,06679+0,05413 \\
& =0,4165 \mathrm{~m} \\
& =41,65 \mathrm{~cm}
\end{aligned}
$$

Sehingga total penurunan konsolidasi pada tip tower 3 totalnya menjadi $0.4165 \mathrm{~m}$. Total penurunan pada tip tower 3 dengan menjumlahkan penurunan elastik serta penurunan konsolidasi yang hanya memikul beban fondasi sendiri totalnya menjadi $0.4175 \mathrm{~m}$. Setelah didapatkan penurunan konsolidasi pada tiang tunggal dilanjutkan dengan perbandingan penurunan tiang kelompok perhitungannya sebagai berikut :

-Lapisan 1 (2.5-5 m)

$$
\begin{array}{ll}
\text { Nilai qc rata-rata } & =2,565 \mathrm{~kg} / \mathrm{cm}^{2} \\
& =2,5154 \mathrm{Bar} \\
\text { Nilai Cc } & =0,2 \text { (asumsi) } \\
\text { Nilai eo } & =0,8 \text { (asumsi) } \\
\text { Tebal Lapisan (h) } & =2,5 \mathrm{~m} \\
\text { Nilai } \gamma \text { saturated } & =16,5 \\
\text { Nilai } \sigma_{0} & =(\gamma \text { saturated }-1) \times h \\
& =(16,5-10) \times 2,5 \\
& =16,25 \mathrm{kN} / \mathrm{m}^{2} \\
& =(\text { volume tiang bor } \times \text { berat jenis beton })+\text { berat pilecap } \\
\text { Besar beban P } & =\left(\left(\left(0,2827 \mathrm{~m}^{2} \times 2,5 \mathrm{~m}\right) \times 24 \mathrm{kN} / \mathrm{m}^{3}\right) \times 4\right)+104,1984 \\
\text { Sisi bidang fiktif } & =510,2284 \mathrm{kN} \\
& =635 \mathrm{~cm} \\
& =6,35 \mathrm{~m} \\
\text { Luas }(\text { A) } & =S^{2} \\
& =6,35^{2} \\
& =40,3225 \mathrm{~m}^{2} \\
& =\frac{P}{A} \\
\text { Nilai } \Delta \sigma & =\frac{510.2284 \mathrm{kN}}{40.3225 \mathrm{~m}^{2}} \\
& =12,6539 \mathrm{kN} / \mathrm{m}^{2} \\
& =\frac{C c . H}{1+e o} \log \frac{\sigma o+\Delta o}{\sigma 0} \\
& =\frac{0.2 \times 5}{1+0.8} \log \frac{16.25+12.6539}{16.25} \\
& =0,06947 \mathrm{~m} \\
& =6,947 \mathrm{~cm} \\
&
\end{array}
$$

-Lapisan 2 (5-10 m) 


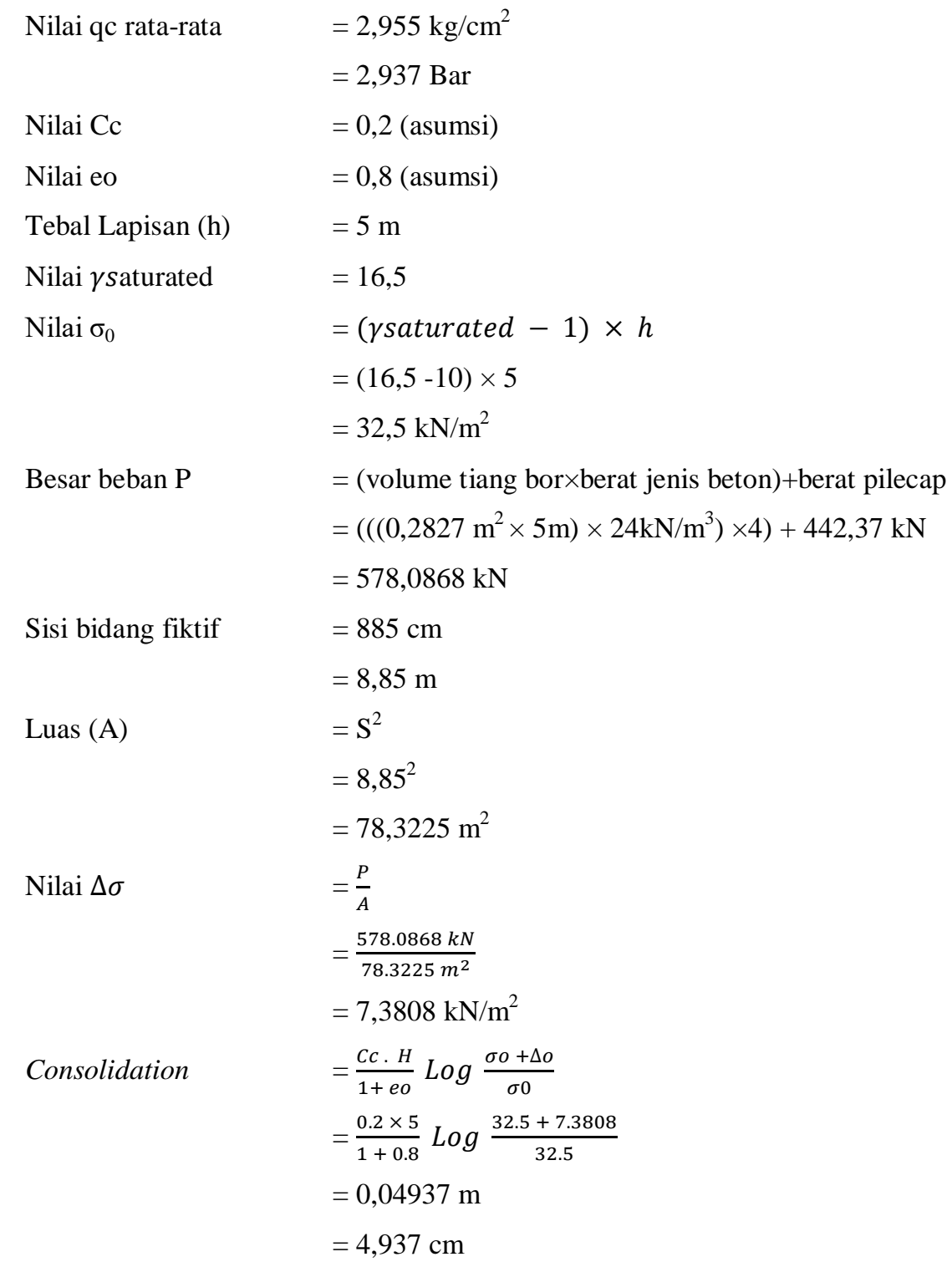

-Lapisan 3 (10-15 m)

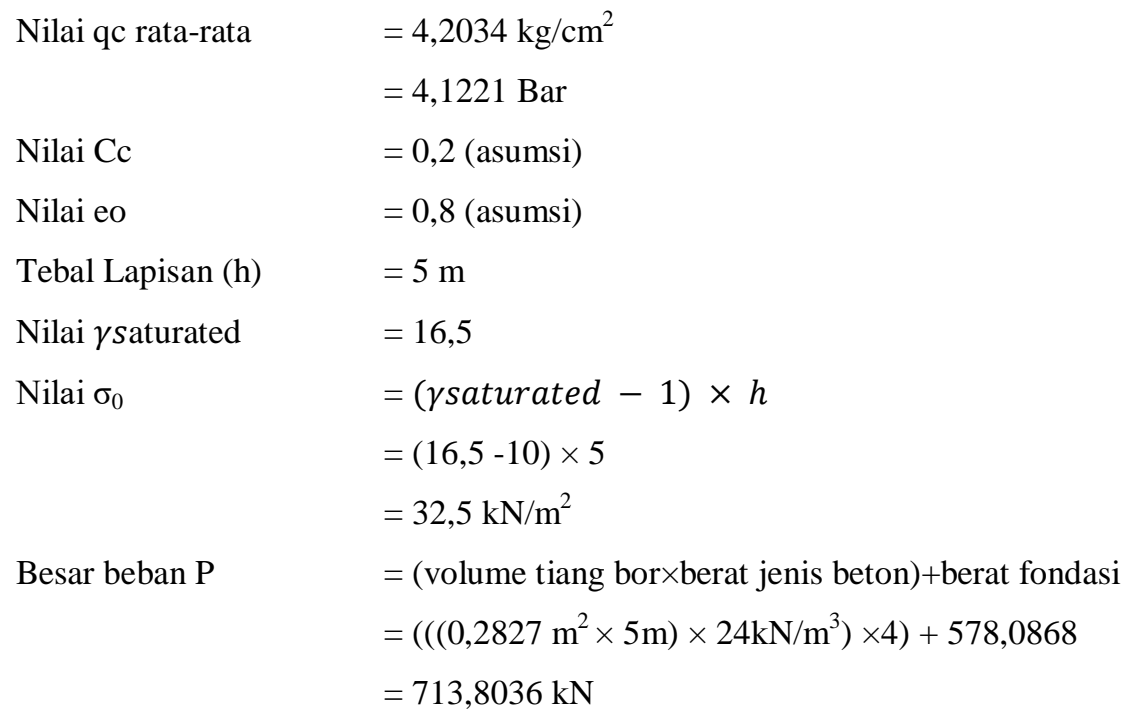




$\begin{aligned} \text { Sisi bidang fiktif } & =1135 \mathrm{~cm} \\ & =11,35 \mathrm{~m} \\ \text { Luas (A) } & =\mathrm{S}^{2} \\ & =11,35^{2} \\ & =128,8225 \mathrm{~m}^{2} \\ \text { Nilai } \Delta \sigma & =\frac{P}{A} \\ & =\frac{713.8036 \mathrm{kN}}{128.8225 \mathrm{~m}^{2}} \\ & =5,5409 \mathrm{kN} / \mathrm{m}^{2} \\ & =\frac{C c . H}{1+e o} \log \frac{\sigma o+\Delta o}{\sigma 0} \\ \text { Consolidation } & =\frac{0.2 \times 5}{1+0.8} \log \frac{32.5+5.5409}{32.5} \\ & =0,03798 \mathrm{~m} \\ & =3,798 \mathrm{~cm}\end{aligned}$

-Lapisan 4 (15-19 m)

$\begin{array}{ll}\text { Nilai qc rata-rata } & =4,9638 \mathrm{~kg} / \mathrm{cm}^{2} \\ & =4,8678 \mathrm{Bar} \\ \text { Nilai Cc } & =0,7 \text { (asumsi) } \\ \text { Nilai eo } & =0,8 \text { (asumsi) } \\ \text { Tebal Lapisan (h) } & =4 \mathrm{~m} \\ \text { Nilai } \gamma \text { saturated } & =16,5 \\ \text { Nilai } \sigma_{0} & =(\gamma \text { saturated }-1) \times h \\ & =(16,5-10) \times 4 \\ & =26 \mathrm{kN} / \mathrm{m}^{2} \\ & =(\text { volume tiang bor } \times \text { berat jenis beton })+\text { berat fondasi } \\ \text { Besar beban P } & =\left(\left(\left(0,2827 \mathrm{~m}^{2} \times 4 \mathrm{~m}\right) \times 24 \mathrm{kN} / \mathrm{m}^{3}\right) \times 4\right)+713,8036 \\ & =849,5204 \mathrm{kN} \\ \text { Sisi bidang fiktif } & =1335 \mathrm{~cm} \\ & =13,35 \mathrm{~m} \\ \text { Luas (A) } & =S^{2} \\ & =13,35^{2} \\ & =178,2225 \mathrm{~m}^{2} \\ & =\frac{P}{A} \\ \text { Consolidation } & =\frac{849.5204 \mathrm{kN}}{178.2225 \mathrm{~m}^{2}} \\ & =4,7666 \mathrm{kN} / \mathrm{m}^{2} \\ & =\frac{C c . H}{1+e o} \log \frac{\sigma o+\Delta o}{\sigma 0} \\ & =\frac{0.2 \times 4}{1+0.8} \log \frac{26+4.7666}{26} \\ & =0,03249 \mathrm{~m} \\ & \end{array}$




$$
=3,249 \mathrm{~cm}
$$

Sc

$$
\begin{aligned}
& =\text { Lapisan } 1+\text { Lapisan } 2+\text { Lapisan } 3+\text { Lapisan } 4 \\
& =0,06947+0,04937+0,03798+0,03249 \\
& =0,1893 \mathrm{~m} \\
& =18,93 \mathrm{~cm}
\end{aligned}
$$

Sehingga total penurunan konsolidasi pada tip tower 3 totalnya menjadi $0,1893 \mathrm{~m}$. Total penurunan pada tip tower 3 dengan menjumlahkan penurunan elastik serta penurunan konsolidasi yang hanya memikul beban fondasi sendiri totalnya menjadi $0,1903 \mathrm{~m}$.

Setelah dilakukan perhitungan penurunan konsolidasi pada tip tower 3 dengan hanya menggunakan beban dari berat

\begin{tabular}{|c|c|}
\hline Nilai qc rata-rata & $=2,565 \mathrm{~kg} / \mathrm{cm}^{2}$ \\
\hline & $=2,5154 \mathrm{Bar}$ \\
\hline Nilai Cc & $=0,2$ (asumsi) \\
\hline Nilai eo & $=0,8$ (asumsi) \\
\hline Tebal Lapisan (h) & $=2,5 \mathrm{~m}$ \\
\hline Nilai $\gamma s$ aturated & $=16,5$ \\
\hline Nilai $\sigma 0$ & $\begin{array}{l}=(\text { rsaturated }-1) \times h \\
=(16,5-10) \times 2,5 \\
=16,25 \mathrm{kN} / \mathrm{m}^{2}\end{array}$ \\
\hline Besar beban $\mathrm{P}$ & $\begin{array}{l}=(\text { berat tiang bor }+ \text { berat pilecap })+\text { berat tower } \\
=510,2284+196,133 \\
=706,3614 \mathrm{kN}\end{array}$ \\
\hline Sisi bidang fiktif & $\begin{array}{l}=635 \mathrm{~cm} \\
=6,35 \mathrm{~m}\end{array}$ \\
\hline Luas (A) & $\begin{array}{l}=S^{2} \\
=6,35^{2}\end{array}$ \\
\hline & $=40,3225 \mathrm{~m}^{2}$ \\
\hline Nilai $\Delta \sigma$ & $\begin{array}{l}=\frac{P}{A} \\
=\frac{638.503 \mathrm{kN}}{40.3225 \mathrm{~m}^{2}}\end{array}$ \\
\hline Consolidation & $\begin{array}{l}=17,5178 \mathrm{kN} / \mathrm{m}^{2} \\
=\frac{C c \cdot H}{1+e o} \log \frac{\sigma o+\Delta o}{\sigma 0} \\
=\frac{0.2 \times 5}{1+0.8} \log \frac{16.25+17.5178}{16.25}\end{array}$ \\
\hline
\end{tabular}
fondasi sendiri berikutnya akan dilakukan perhitungan seberapa besar penurunan pada konsolidasi jika dimasukkan beban dari berat tower jaringan transmisi $150 \mathrm{kV}$ yang akan dipikul oleh fondasi. Dimana pada tip tower 3 jenis tower transmisi yang digunakan adalah tipe BB, pada umumnya berat total jenis tower BB sekitar 20 ton.

-Lapisan 1 (2.5-5 m) 


$$
\begin{aligned}
& =0,08823 \mathrm{~m} \\
& =8,823 \mathrm{~cm}
\end{aligned}
$$

-Lapisan 2 (5-10 m)

\begin{tabular}{|c|c|}
\hline Nilai qc rata-rata & $=2,525 \mathrm{~kg} / \mathrm{cm}^{2}$ \\
\hline & $=2,4761 \mathrm{Bar}$ \\
\hline Nilai Cc & $=0,2$ (asumsi) \\
\hline Nilai eo & $=0,8$ (asumsi) \\
\hline Tebal Lapisan (h) & $=5 \mathrm{~m}$ \\
\hline Nilai $\gamma s$ aturated & $=16,5$ \\
\hline Nilai $\sigma 0$ & $\begin{array}{l}=(\gamma \text { saturated }-1) \times h \\
=(16,5-10) \times 5\end{array}$ \\
\hline
\end{tabular}

$$
\begin{aligned}
& \text { Nilai qc rata-rata } \quad=2,0976 \mathrm{~kg} / \mathrm{cm}^{2} \\
& =2,057 \mathrm{Bar} \\
& \text { Nilai Cc } \quad=0,2 \text { (asumsi) } \\
& \text { Nilai eo } \quad=0,8 \text { (asumsi) } \\
& \text { Tebal Lapisan }(\mathrm{h}) \quad=5 \mathrm{~m} \\
& \text { Nilai } \gamma s \text { aturated } \quad=16,5 \\
& \text { Nilai } \sigma_{0} \quad=(\text { rsaturated }-1) \times h \\
& =(16,5-10) \times 5 \\
& =32,5 \mathrm{kN} / \mathrm{m}^{2} \\
& \text { Besar beban } \mathrm{P} \quad \text { = (berat tiang bor }+ \text { berat pilecap })+ \text { berat tower } \\
& =578,0868+196,133 \\
& =774,2198 \mathrm{kN} \\
& \text { Sisi bidang fiktif } \quad=885 \mathrm{~cm} \\
& =8,85 \mathrm{~m} \\
& \text { Luas (A) } \quad=\mathrm{S}^{2} \\
& =8,85^{2} \\
& =78,3225 \mathrm{~m}^{2} \\
& =\frac{774.2198 \mathrm{kN}}{78.3225 \mathrm{~m}^{2}} \\
& =9,8850 \mathrm{kN} / \mathrm{m}^{2} \\
& =\frac{C c \cdot H}{1+e o} \log \frac{\sigma o+\Delta o}{\sigma 0} \\
& =\frac{0.2 \times 5}{1+0.8} \log \frac{32.5+9.8850}{32.5} \\
& =0,06407 \mathrm{~m} \\
& =6,407 \mathrm{~cm}
\end{aligned}
$$

-Lapisan 3 (10-15 m) 


$$
\begin{array}{ll} 
& =32,5 \mathrm{kN} / \mathrm{m}^{2} \\
\text { Besar beban P } & =(\text { berat tiang bor }+ \text { berat pilecap })+\text { berat tower } \\
& =713,8036+196,133 \\
& =909,9366 \mathrm{kN} \\
\text { Sisi bidang fiktif } & =1135 \mathrm{~cm} \\
& =11,35 \mathrm{~m} \\
& =S^{2} \\
& =11,35^{2} \\
& =128,8225 \mathrm{~m}^{2} \\
\text { Nuas (A) } & =\frac{P}{A} \\
& =\frac{909.9366 \mathrm{kN}}{128.8225 \mathrm{~m}^{2}} \\
& =7,0634 \mathrm{kN} / \mathrm{m}^{2} \\
& =\frac{C c . H}{1+e o} \log \frac{\sigma o+\Delta o}{\sigma 0} \\
& =\frac{0.7 \times 5}{1+0.8} \mathrm{Log} \frac{32.5+7.0634}{32.5} \\
& =0,04745 \mathrm{~m} \\
& =4,745 \mathrm{~cm}
\end{array}
$$

-Lapisan 4 (15-19 m)

$$
\begin{aligned}
& \text { Nilai qc rata-rata } \quad=4,9638 \mathrm{~kg} / \mathrm{cm}^{2} \\
& =4,8678 \mathrm{Bar} \\
& \text { Nilai Cc =0,27 (asumsi) } \\
& \text { Nilai eo } \quad=0,8 \text { (asumsi) } \\
& \text { Tebal Lapisan }(\mathrm{h}) \quad=4 \mathrm{~m} \\
& \text { Nilai } \gamma s \text { aturated } \quad=16,5 \\
& \text { Nilai } \sigma_{0} \quad=(\gamma \text { saturated }-1) \times h \\
& =(16,5-1) \times 4 \\
& =26 \mathrm{kN} / \mathrm{m}^{2} \\
& \text { Besar beban } \mathrm{P} \quad \text { = (berat tiang bor }+ \text { berat pilecap })+ \text { berat tower } \\
& =849,5204+196,133 \\
& =1045,653 \mathrm{kN} \\
& \text { Sisi bidang fiktif } \quad=1335 \mathrm{~cm} \\
& =13,35 \mathrm{~m} \\
& \text { Luas (A) } \quad=\mathrm{S}^{2} \\
& =13,35^{2} \\
& =178,2225 \mathrm{~m}^{2}
\end{aligned}
$$




$$
=5,8671 \mathrm{kN} / \mathrm{m}^{2}
$$

Consolidation

$$
\begin{aligned}
& =\frac{C c \cdot H}{1+e o} \log \frac{\sigma o+\Delta o}{\sigma 0} \\
& =\frac{0.2 \times 5}{1+0.8} \log \frac{26+5.8671}{26} \\
& =0,03927 \mathrm{~m} \\
& =3,927 \mathrm{~cm}
\end{aligned}
$$

Sc

$$
\begin{aligned}
& =\text { Lapisan } 1+\text { Lapisan } 2+\text { Lapisan } 3+\text { Lapisan } 4 \\
& =0,08823+0,06407+0,04745+0,03927 \\
& =0,2390 \mathrm{~m} \\
& =23,9 \mathrm{~cm}
\end{aligned}
$$

Sehingga total penurunan konsolidasi pada tip tower 3 dengan adanya tambahan beban tower penurunannya menjadi $0,2390 \mathrm{~m}$. Total penurunan pada tip tower 3 dengan menjumlahkan penurunan elastik serta penurunan konsolidasi yang hanya memikul beban fondasi sendiri totalnya menjadi $0,24008 \mathrm{~m}$.

\section{Kesimpulan elastic settlement}

Berdasarkan jenis lapisan tanah yang diperoleh serta beban yang akan dipikul telah diketahui, berikutnya parameterparameter yang telah diperoleh maka data tanah dapat dikorelasikan dan dapat digunakan sebagai asumsi untuk melakukan perhitungan elastic settlement, maka penurunan elastis pada masing-masing tip tower yaitu pada tip tower 3 dan tip tower 4 dapat dilihat pada tabel berikut

Tabel 1. Tabel elastic settlement

\begin{tabular}{ccc}
\hline & Tip Tower 3 & Tip Tower 4 \\
\hline $\begin{array}{c}\text { Elastic } \\
\text { Settlement }\end{array}$ & $0,1081 \mathrm{~cm}$ & $0,4022 \mathrm{~cm}$ \\
\hline
\end{tabular}

\section{Consolidation settlement}

Berdasarkan dari aparmeter-parameter tanah yang telah dikorelasikan dan telah ditentukan, kemudian nilai-nilai tersebut dimasukkan ke dalam rumus untuk mengetahui besar consolidation settlement yang terjadi pada masingmasin tip tower 3 dan tip tower 4 . Untuk perhitungan besar penurunan yang terjadi dibedakan menjadi 2 yaitu besar consolidation settlement tanpa adanya beban dari tower hanya beban dari fondasi sendiri dan consolidation settlement dengan adanya beban tower atau tower telah berdiri tegak. Besarnya consolidation settlement pada masing-masing tip tower yaitu tip tower 3 dan tip tower 4 dapat dilihat pada tabel berikut

Tabel 2. Tabel consolidation settlement

\begin{tabular}{ccc}
\hline & Tip Tower 3 & Tip Tower 4 \\
\hline $\begin{array}{l}\text { Penurunan Konsolidasi Tiang } \\
\text { Tunggal Tanpa Beban Tower }\end{array}$ & $41,75 \mathrm{~cm}$ & $45,38 \mathrm{~cm}$ \\
\hline $\begin{array}{c}\text { Penurunan Konsolidasi Tiang } \\
\text { Kelompok Tanpa Beban Tower }\end{array}$ & $19,03 \mathrm{~cm}$ & $22,61 \mathrm{~cm}$ \\
\hline
\end{tabular}




\begin{tabular}{ccc}
\hline $\begin{array}{c}\text { Penurunan Konsolidasi di } \\
\text { Lapangan }\end{array}$ & $15 \mathrm{~cm}$ & $0 \mathrm{~cm}$ \\
\hline $\begin{array}{c}\text { Penurunan Konsolidasi Tiang } \\
\text { Kelompok Dengan Beban }\end{array}$ & $24,008 \mathrm{~cm}$ & \\
Tower & & $29,58 \mathrm{~cm}$ \\
\hline
\end{tabular}

\section{KESIMPULAN}

Dapat disimpulkan dari perhitungan konsolidasi yang terjadi perhitungan konsolidasi pada tip tower 3 yang paling mendekati kondisi sebenarnya di lapangan adalah penurunan konsolidasi tiang kelompok. Sedangkan untuk tip tower 4 untuk kondisi di lapangan ada kemungkinan konsolidasi belum terjadi karena konsolidasi memerlukan waktu yang lama untuk terjadi.

\section{DAFTAR PUSTAKA}

Poulos, H. G. dan E. H. Davis. Pile Foundation Analysis and Design. Canada: The University of Sydney, 1980.

Terzaghi, K. and Peck, R.B., (1967), "Soil Mechanics in Engineering Practice”, John Wiley \& Sons, New York, 729 pp 